\title{
Erratum to: Optimal Control Applications for Operations Strategy
}

\author{
Bowon Kim
}

\section{Erratum to:}

B. Kim, Optimal Control Applications for Operations Strategy, DOI 10.1007/978-981-10-3599-9

In the original version of the book, the newly received corrections have to be incorporated in Chapters 1-5. The erratum book has been updated with the changes.

The updated online version of this book can be found at

http://dx.doi.org/10.1007/978-981-10-3599-9

http://dx.doi.org/10.1007/978-981-10-3599-9_1

http://dx.doi.org/10.1007/978-981-10-3599-9_2

http://dx.doi.org/10.1007/978-981-10-3599-9_3

http://dx.doi.org/10.1007/978-981-10-3599-9_4

http://dx.doi.org/10.1007/978-981-10-3599-9_5

(C) Springer Nature Singapore Pte Ltd. 2017 